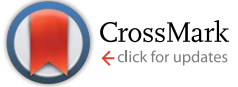

Cite this: J. Mater. Chem. A, 2014, 2 , 12754

Received 17th March 2014

Accepted 31st May 2014

DOI: $10.1039 / \mathrm{c} 4 \mathrm{ta0} 1310 \mathrm{~g}$

www.rsc.org/MaterialsA

\section{Organo-metal halide perovskite-based solar cells with CuSCN as the inorganic hole selective contact $\uparrow$}

\begin{abstract}
Sudam Chavhan, ${ }^{a}$ Oscar Miguel, ${ }^{a}$ Hans-Jurgen Grande, ${ }^{a}$ Victoria Gonzalez-Pedro, ${ }^{b}$ Rafael S. Sánchez, ${ }^{\mathrm{b}}$ Eva M. Barea, ${ }^{\mathrm{b}}$ Iván Mora-Seró*b and Ramón Tena-Zaera*a

CuSCN is proposed as a cost-competitive hole selective contact for the emerging organo-metal halide perovskite-based solar cells. The CuSCN films have been deposited by a solution casting technique, which has proven to be compatible with the perovskite films, obtaining planar-like heterojunction-based glass/FTO/ $\mathrm{TiO}_{2} / \mathrm{CH}_{3} \mathrm{NH}_{3} \mathrm{Pbl}_{3-x} \mathrm{Cl}_{x} / \mathrm{CuSCN} / \mathrm{Au}$ solar cells with a power conversion efficiency of $6.4 \%$. Among the photovoltaic parameters, the fill factor (i.e. 62\%) suggests good carrier selectivity and, therefore, efficient functionality of the $\mathrm{TiO}_{2}$ and $\mathrm{CuSCN}$ charge carrier selective contacts. However, the open-circuit voltage $\left(V_{\text {oc }}\right)$, which remains low in comparison with the state of the art perovskite-based solar cells, appears to be the main limiting parameter. This is attributed to the short diffusion length as determined by impedance spectroscopy. However, the recombination losses are not only affected by the CuSCN, but also by the perovskite film. Indeed, variations of $20^{\circ} \mathrm{C}$ in the thermal annealing of the perovskite films result in changes larger than $200 \mathrm{mV}$ in the $V_{\text {oc }}$. Furthermore, a detailed analysis of the quantum efficiency spectra contributes significant insights into the influence of the selective contacts on the photocurrent of the planar heterojunction perovskite solar cells.
\end{abstract}

\section{Introduction}

Previously investigated as light emitters, ${ }^{\mathbf{1}}$ the organometal methyl ammonium lead trihalide perovskites $\left(\mathrm{CH}_{3} \mathrm{NH}_{3} \mathrm{PbX}_{3}\right.$, where $\mathrm{X}=\mathrm{I}, \mathrm{Cl}, \mathrm{Br}$ ) have recently emerged as promising photovoltaic materials because of their unique combination of versatile processing and superior opto-electronic properties such as large absorption coefficient and ambipolar charge transport. The extremely rapid evolution of the perovskite-based solar cells during the last 2 years, ${ }^{2-7}$ reaching power conversion efficiencies up to $16.2 \%$ (ref. 8 ) makes them a very appealing cost- and performance-competitive emerging technology for photovoltaics.

Different alternatives of methyl ammonium lead trihalide perovskites, such as $\mathrm{CH}_{3} \mathrm{NH}_{3} \mathrm{PbI}_{3},{ }^{2,9} \quad \mathrm{CH}_{3} \mathrm{NH}_{3} \mathrm{PbI}_{3-x} \mathrm{Cl}_{x},{ }^{3}$ $\mathrm{CH}_{3} \mathrm{NH}_{3} \mathrm{PbBr}_{3}$ (ref. 10 and 11) and $\mathrm{CH}_{3} \mathrm{NH}_{3} \mathrm{PbI}_{3-x} \mathrm{Br}_{x}{ }^{12}$ have been investigated for the development of photovoltaic devices. But, in addition to the solar light harvester material, appropriate electron and hole selective contacts are being used in order to minimize the charge carrier recombination ${ }^{\mathbf{1 3}}$ and

${ }^{a}$ Energy Division, IK4-CIDETEC, Parque Tecnológico de San Sebastián, Paseo Miramón 196, Donostia-San Sebastián 20009, Spain. E-mail: rtena@cidetec.es

${ }^{b}$ Photovoltaics and Optoelectronic Devices Group, Departament de Fisica, Universitat Jaume I, 12071 Castello, Spain.E-mail: sero@uji.es

† Electronic supplementary information (ESI) available. See DOI: $10.1039 / \mathrm{c} 4 \mathrm{ta} 01310 \mathrm{~g}$ consequent losses in the solar cell performance. Although the viability of using organic electron selective contacts $($ e.g. $(6,6)$ phenyl C61-butyric acid methyl ester (PCBM) $)^{\mathbf{1 4 , 1 5}}$ has been recently demonstrated, the best performance perovskite solar cells are based on metal oxides such as $\mathrm{ZnO}^{7}$ and $\mathrm{TiO}_{2}$ (ref. 4 and 5) or hybrid derivative nanocomposites. ${ }^{6}$ In contrast, the research on the selective hole contacts has been mainly focused on organic compounds such as 2,2(7,7(-tetrakis- $(N, N$ di- $p$-methoxyphenylamine)9,9(-spirobifluorene))) (spiro-OMeTAD) ${ }^{2,3}$ poly-3-hexylthiophene (P3HT), ${ }^{16}$ (poly-[[9-(1-octylnonyl)9H-carbazole-2,7-diyl]-2,5-thiophenediyl-2,1,3-benzothiadiazole4,7-diyl-2,5-thiophenediyl]) (PCDTBT), ${ }^{17}$ poly-triarylamine (PTAA), ${ }^{12}$ 4-(diethylamino)-benzaldehyde diphenylhydrazone $(\mathrm{DEH})^{\mathbf{1 8}}$ and $N, N^{\prime}$-dialkyl perylenediimide (PDI) ${ }^{11}$ Among them, the spiro-OMeTAD demonstrated the best device performance. ${ }^{5,6}$ However, its relatively high cost may represent a potential bottleneck for the future commercialization of perovskite solar cells. Solution processed inorganic p-type semiconductors appear to be an appealing cost-effective alternative for hole selective contacts. Furthermore, the integration of inorganic films could pave the way to obtain devices insensitive to the ambient environment. Therefore, the integration of inorganic selective contacts may have significant beneficial impact on the production cost and robustness of the perovskite solar cell technology. Nevertheless, to the best of our knowledge, there is only one report on the use of inorganic hole selective contacts i.e. CuI. ${ }^{19}$ However, CuSCN appears to be a 
good candidate because of its good performance as a hole transport material in different kinds of photovoltaic technologies such as solid-state dye-sensitized, ${ }^{20,21}$ semiconductorsensitized $^{22,23}$ and polymer solar cells. ${ }^{24}$

In this paper, the viability of using CuSCN as a hole selective contact has been demonstrated in planar heterojunction-based glass/FTO/TiO $/ \mathrm{CH}_{3} \mathrm{NH}_{3} \mathrm{PbI}_{3-x} \mathrm{Cl}_{x} / \mathrm{CuSCN} / \mathrm{Au}$ solar cells with a power conversion efficiency of $6.4 \%$. As far as we know, this is the highest reported efficiency for the perovskite solar cells with inorganic hole selective contacts. Furthermore, the effect of the annealing temperature on the microstructural properties of the perovskite films and its influence on the solar cell performance has been investigated. The characterization of the devices has been carried out by measuring their current-voltage characteristics under dark and simulated sun irradiation, external quantum efficiency spectra and impedance spectroscopy (IS). The high recombination is pointed out as the main origin of the modest photovoltage $(<750 \mathrm{mV})$ in comparison with other perovskite solar cells, which is the main limiting photovoltaic parameter. The well-balanced charge carrier extraction in the selective contacts is proposed as a key to reach high photocurrents in the planar heterojunction perovskite solar cells. In particular, the influence of the hole selective contact on the solar cell performance is emphasized.

\section{Experimental section}

\section{Deposition of organo-metal halide perovskite films}

Organo-metal halide perovskite films were deposited from $3 \mathrm{M}$ $\mathrm{CH}_{3} \mathrm{NH}_{3} \mathrm{I}^{9}$ and $1 \mathrm{M} \mathrm{PbCl}_{2}$ (>98\%, Sigma Aldrich) in anhydrous $N, N$-dimethylformamide (DMF) solution. ${ }^{25}$ In order to follow the same nomenclature as in previous reports, ${ }^{26}$ the obtained films will be hereafter referred to as $\mathrm{CH}_{3} \mathrm{NH}_{3} \mathrm{PbI}_{3-x} \mathrm{Cl}_{x}$ although unambiguous proof about the chlorine content cannot be provided. The $\mathrm{CH}_{3} \mathrm{NH}_{3} \mathrm{PbI}_{3-x} \mathrm{Cl}_{x}$ films were processed on glass/ $\mathrm{SnO}_{2}: \mathrm{F} / \mathrm{TiO}_{2}$ substrates by spin coating at $700 \mathrm{rpm}$ for $60 \mathrm{~s}$ then at $2000 \mathrm{rpm}$ for $60 \mathrm{~s}$, and annealed on a hot plate at 90, 100, 110, and $120{ }^{\circ} \mathrm{C}$ for $3 \mathrm{~h}$. The deposition and annealing treatments of $\mathrm{CH}_{3} \mathrm{NH}_{3} \mathrm{PbI}_{3-x} \mathrm{Cl}_{x}$ films were carried out in an argon-filled glove-box.

\section{Thin film characterization techniques}

The optical transmittance and reflectance of the glass $/ \mathrm{SnO}_{2}: \mathrm{F} /$ $\mathrm{TiO}_{2} / \mathrm{CH}_{3} \mathrm{NH}_{3} \mathrm{PbI}_{3-x} \mathrm{Cl}_{x}$ samples were measured at room temperature with a Jascow V-570 spectrophotometer fitted with an integrating sphere, from 300 to $900 \mathrm{~nm}$. The morphology and structural properties of the films were analyzed using a ULTRA plus ZEISS field emission scanning electron microscope (FESEM) and a Bruker AXS-D8 Advance X-ray diffractometer (XRD) using $\mathrm{Cu} \mathrm{K} \alpha$ radiation.

The PL spectra of the films were recorded by using a spectrophotometer based on a CCD (Andor i-DUS DV420A-OE) coupled with a spectrograph as a diffraction grating (Newport 77400). Commercial blue (405 $\mathrm{nm}, 84 \mathrm{~mW} \mathrm{~cm}^{-2}$ ) and red laser diodes ( $650 \mathrm{~nm}, 319 \mathrm{~mW} \mathrm{~cm}^{-2}$ ) were used as excitation sources, whose power was adjusted by means of a mechanical pinhole.

\section{Solar cell preparation}

Glass $/ \mathrm{SnO}_{2}: \mathrm{F}$ (FTO) substrates were cleaned with soap solution and ethanol in an ultrasound bath for $30 \mathrm{~min}$. In order to avoid the direct contact between FTO and hole transporting material (HTM), a ca. $60 \mathrm{~nm}$ thick dense $\mathrm{TiO}_{2}$ layer is deposited onto the FTO by a spray pyrolysis technique. Briefly, $12 \mathrm{~g}$ of titanium isopropoxide (IV) (Aldrich) and $12 \mathrm{~g}$ of acetylacetone (Aldrich) were added to $20 \mathrm{~mL}$ absolute ethanol; during the deposition of $\mathrm{TiO}_{2}$, the substrate temperature was maintained at $450{ }^{\circ} \mathrm{C}$ and subsequently calcined at $450{ }^{\circ} \mathrm{C}$ for $30 \mathrm{~min}$.

After the $\mathrm{CH}_{3} \mathrm{NH}_{3} \mathrm{PbI}_{3-x} \mathrm{Cl}_{x}$ deposition and thermal annealing, the CuSCN film was deposited by drop-casting from a saturated solution of CuSCN in propylsulfide. The solution was pumped at a constant rate of $27 \mu \mathrm{L} \mathrm{min}^{-1}$ using a syringe pump. During the CuSCN deposition, the glass $/ \mathrm{SnO}_{2}: \mathrm{F} / \mathrm{TiO}_{2} / \mathrm{CH}_{3} \mathrm{NH}_{3}$ $\mathrm{PbI}_{3-x} \mathrm{Cl}_{x}$ samples were kept at $85{ }^{\circ} \mathrm{C}$ on a hot plate. In order to control the CuSCN film thickness, $18 \mu \mathrm{L}$ of solution were allowed to drop per $\mathrm{cm}^{2}$ of the sample. An array of gold dots, $0.35 \mathrm{~cm}$ in diameter, was deposited as the back contact by thermal evaporation under $>5 \times 10^{-6}$ Torr vacuum pressure using NANO38 equipment.

\section{Solar cell characterization}

The current-voltage characteristic of the cells were measured using a xenon arc lamp simulator (Sun 2000, ABET Technologies) with an AM 1.5 G spectral filter, and the intensity was adjusted to provide 1 sun $\left(100 \mathrm{~mW} \mathrm{~cm}^{-2}\right)$ using a calibrated silicon solar cell. The active area was defined to be $0.07 \mathrm{~cm}^{2}$ by using an opaque mask. The spectral response of the device photocurrent was measured using a computerized home-built setup (xenon arc lamp, chopper, monochromator, lock-in amplifier). The external quantum efficiency (eQE) was calculated using a standard Si photodiode. The impedance spectroscopy data were recorded with a FRA-equipped PGSTAT-30 from Autolab and the measurements were carried out under illumination conditions at forward bias, applying a $20 \mathrm{mV} \mathrm{AC}$ sinusoidal signal, ranging between $400 \mathrm{kHz}$ and $0.05 \mathrm{~Hz}$, over the constant applied bias.

\section{Results and discussion}

\section{Microstructural properties of $\mathrm{CH}_{3} \mathrm{NH}_{3} \mathrm{PbI}_{3-x} \mathrm{Cl}_{x}$ films}

At first, the morphology of the $\mathrm{CH}_{3} \mathrm{NH}_{3} \mathrm{PbI}_{3-x} \mathrm{Cl}_{x}$ films and its evolution with the annealing temperature was investigated by FE-SEM. Fig. 1 shows representative top-view FE-SEM micrographs of the perovskite films annealed at 90, 100, 110, and $120{ }^{\circ} \mathrm{C}$ for $3 \mathrm{~h}$ in a glove box. Films with a relatively low density of pin-holes were obtained for the lowest annealing temperature. However, the increase of the temperature induced a transition from continuous films to rather discrete islands. Indeed, large areas of naked $\mathrm{TiO}_{2}$ can be detected for samples annealed at $120{ }^{\circ} \mathrm{C}$. The formation of large grains as the annealing temperature increases is emphasized in the high magnification top-view FE-SEM micrographs. It is noted that only a partial view of a representative single grain, which is larger than the micrograph area, is shown for the sample annealed at $120{ }^{\circ} \mathrm{C}$. 

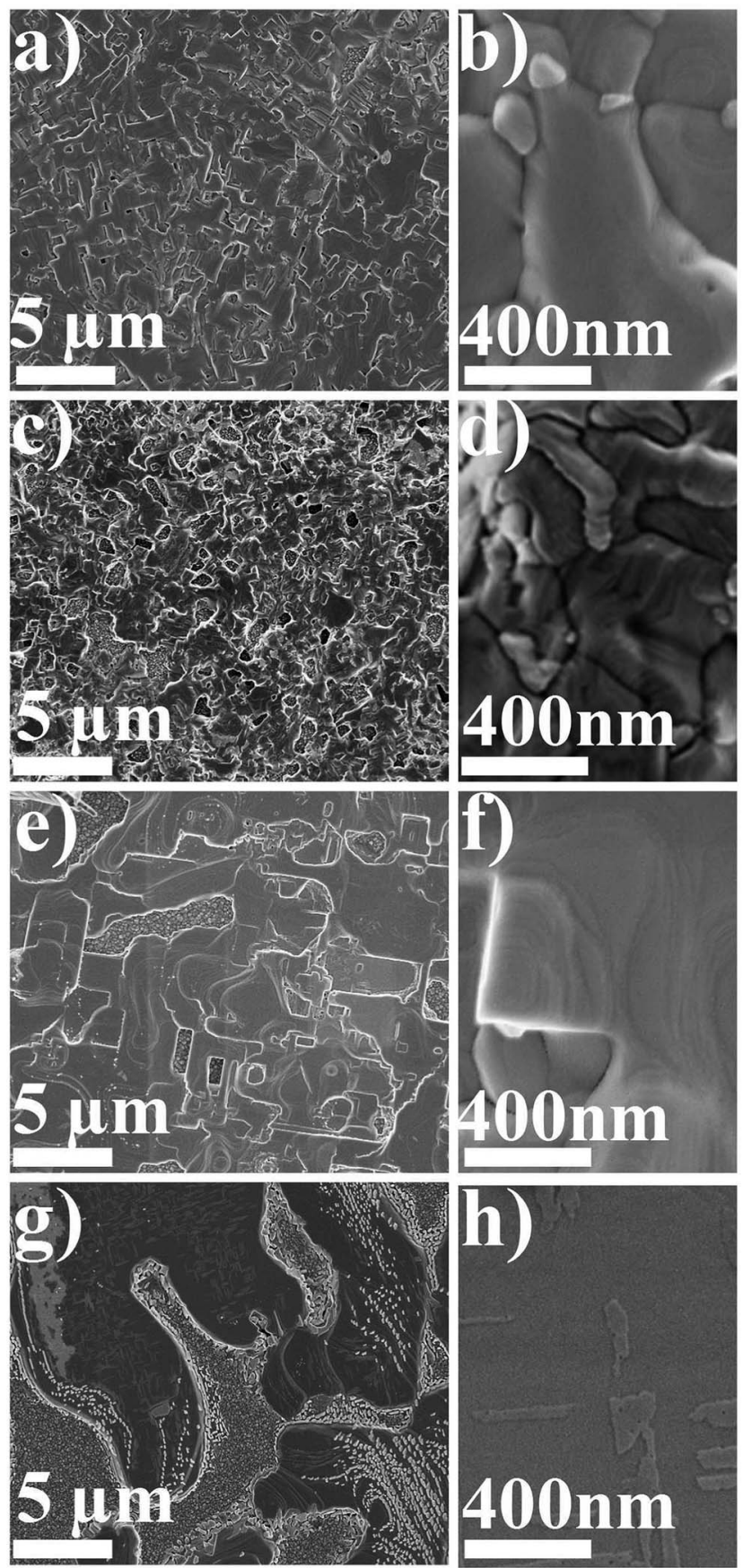

Fig. 1 Top-view: FE-SEM micrographs of the $\mathrm{CH}_{3} \mathrm{NH}_{3} \mathrm{Pbl}_{3-x} \mathrm{Cl}_{x}$ films annealed at: (a \& b) 90, (c \& d) 100, (e \& f) 110, and ( $\&$ \& h) $120{ }^{\circ} \mathrm{C}$ for 3 hours in an argon-filled glove box.

Although the morphology variation trend versus the temperature is similar to that previously reported by Snaith's group, ${ }^{25}$ the present films seem to exhibit stronger sensitivity to the temperature. Interestingly, significantly higher surface coverage is also detected here. Indeed, we obtained perovskite films with much lower coverage by using $\mathrm{CH}_{3} \mathrm{NH}_{3} \mathrm{I}$ synthesized by the same route as in ref. 25 (Fig. S1, ESI†).

The structural properties were analyzed by XRD in the BraggBrentano configuration. Fig. 2 displays the XRD patterns of the

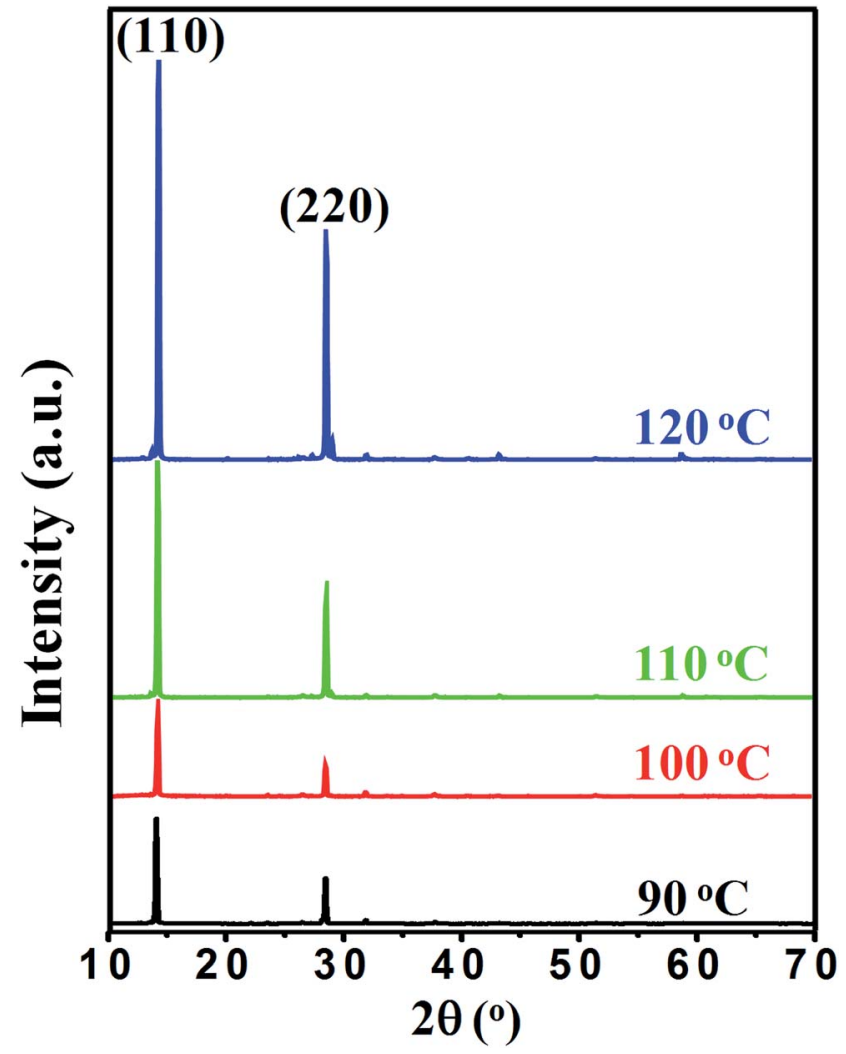

Fig. 2 X-ray diffraction pattern of $\mathrm{FTO} / \mathrm{TiO}_{2 \mathrm{sp}} / \mathrm{CH}_{3} \mathrm{NH}_{3} \mathrm{Pbl}_{3-x} \mathrm{Cl}_{x}$ samples annealed at different temperatures for 3 hours in an argonfilled glove box.

glass/FTO/TiO $2 / \mathrm{CH}_{3} \mathrm{NH}_{3} \mathrm{PbI}_{3-x} \mathrm{Cl}_{x}$ samples annealed at different temperatures. The tetragonal $\mathrm{CH}_{3} \mathrm{NH}_{3} \mathrm{PbI}_{3}$ phase ${ }^{1}$ can be confirmed. The relatively strong intensity of the peaks versus those from the substrate, which are almost not detectable in the linear scale, indicates the good crystallinity of the deposited films. Furthermore, the intensity of the peaks increases significantly with the annealing temperature. In contrast, the full width at half maximum (FWHM) of the peaks is constant regardless of the annealing temperature (Fig. S2a, ESI†). This finding suggests the instrumental broadening as the main contribution to the peak width.

Therefore, is not possible to monitor, by XRD, the evolution of the crystallite size. In addition to the $\mathrm{CH}_{3} \mathrm{NH}_{3} \mathrm{PbI}_{3}$ phaserelated features, a minor peak occurring at $2 \theta \sim 13.55^{\circ}$, which is characteristic of films deposited from $\mathrm{PbCl}_{2},{ }^{3,27}$ is also detected (Fig. S2b, ESI $\dagger$ ). Furthermore, a very weak intensity feature is observed at $2 \theta \sim 12.75^{\circ}$, suggesting the presence of minor traces of the $\mathrm{PbI}_{2}$ phase in the films. Interestingly, the intensity of the peak increases with the annealing temperature. Very recently, Dualeh et $a l .{ }^{27}$ reported a similar finding and suggested the relatively fast sublimation of the organic species as a potential origin.

\section{Solar cells}

In order to evaluate the viability of CuSCN as a hole selective contact in perovskite solar cells, CuSCN thin films were 
deposited on the glass $/ \mathrm{SnO}_{2}: \mathrm{F} / \mathrm{TiO}_{2} / \mathrm{CH}_{3} \mathrm{NH}_{3} \mathrm{PbI}_{3-x} \mathrm{Cl}_{x}$ samples. As a result, a hybrid multilayer heterostructure (i.e. $\mathrm{TiO}_{2} /$ $\mathrm{CH}_{3} \mathrm{NH}_{3} \mathrm{PbI}_{3-x} \mathrm{Cl}_{x} / \mathrm{CuSCN}$ ) was obtained by a three-step deposition process. Fig. 3 shows the FE-SEM micrographs of the samples after each step, monitoring the sequential deposition of compact $\mathrm{TiO}_{2}$, perovskite and CuSCN films with mean thicknesses of 60, 400 and $500 \mathrm{~nm}$, respectively. As previously reported, ${ }^{5}$ significant deviations in the local thickness of the perovskite film were detected (Fig. S3, ESI $\dagger$ ). Although these local variations made difficult accurate comparative analyses for the perovskite thickness before and after the CuSCN deposition, no significant changes in the mean value were detected. Thus, it can be concluded that there is not a significant dissolution of the perovskite during the CuSCN deposition solution step.

Fig. 4 shows the current density-voltage curves recorded for $\mathrm{TiO}_{2} / \mathrm{CH}_{3} \mathrm{NH}_{3} \mathrm{PbI}_{3-x} \mathrm{Cl}_{x} / \mathrm{CuSCN}$ solar cells, based on perovskite films annealed at different temperatures, under illumination of $100 \mathrm{~mW} \mathrm{~cm} \mathrm{~cm}^{-2}$ simulated sun-light (1.5 AM). The solar cell performance is strongly influenced by the annealing temperature of the perovskite film, i.e. influenced by the effect of the
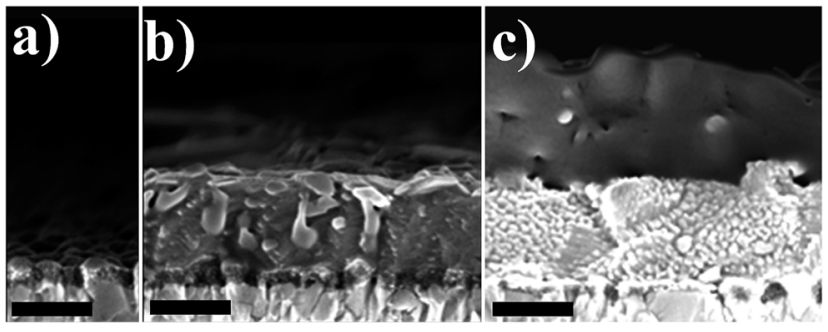

Fig. 3 Cross-section FE-SEM micrographs of (a) $\mathrm{FTO} / \mathrm{TiO}_{2 \mathrm{sp}}$, (b) FTO/ $\mathrm{TiO}_{2 \mathrm{sp}} / \mathrm{CH}_{3} \mathrm{NH}_{3} \mathrm{Pbl}_{3-x} \mathrm{Cl}_{x}$ and (c) $\mathrm{FTO} / \mathrm{TiO}_{2 \mathrm{sp}} / \mathrm{CH}_{3} \mathrm{NH}_{3} \mathrm{Pbl}_{3-x} \mathrm{Cl}_{x^{\prime}} /$ CuSCN ( $400 \mathrm{~nm}$ scale).

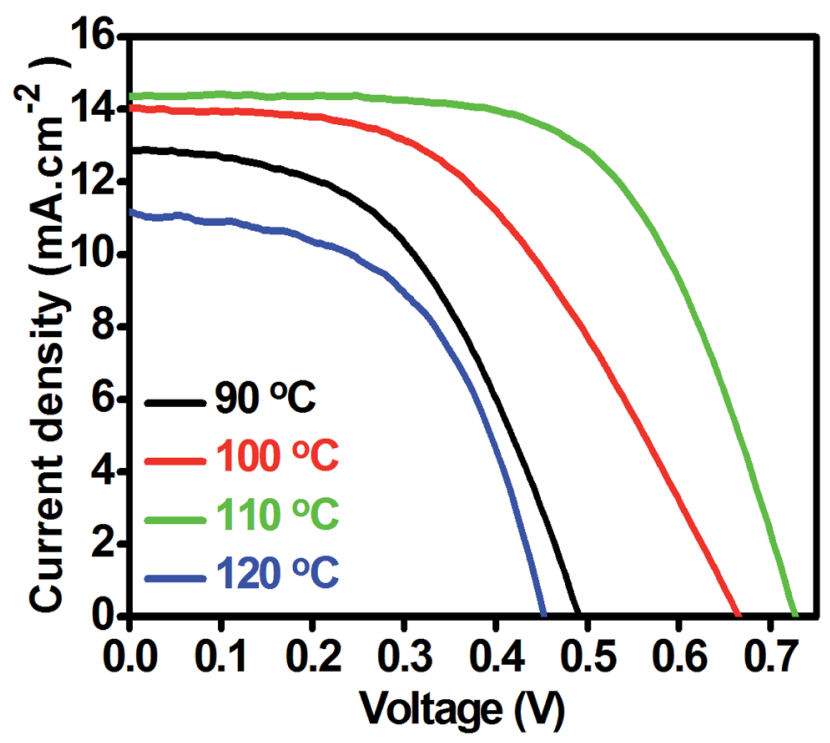

Fig. 4 Current density-voltage curves of solar cells, based on $\mathrm{CH}_{3} \mathrm{NH}_{3} \mathrm{Pbl}_{3-x} \mathrm{Cl}_{x}$ films annealed at different temperatures, under illumination of $100 \mathrm{~mW} \mathrm{~cm}^{-2}$ simulated sun irradiation (1.5 AM). crystallinity and continuity of the perovskite film. The solar cell parameters extracted from the $J-V$ curves are summarized in Table 1. From Table 1, remarkable influence of the annealing temperature on the FF and $V_{\mathrm{oc}}$ values is noticed. The enhancement in solar cell performance is particularly dramatic for an annealing temperature of $110{ }^{\circ} \mathrm{C}$, leading to $6.4 \%$ power conversion efficiency for the champion cell. To the best of our knowledge, this is the first efficiency reported for perovskite based solar cell employing CuSCN as a hole selective contact, and the highest one obtained for inorganic semiconductorbased hole selective contact in perovskite solar cells. ${ }^{19}$ A histogram of the power conversion efficiency for 168 devices prepared from $\mathrm{CH}_{3} \mathrm{NH}_{3} \mathrm{PbI}_{3-x} \mathrm{Cl}_{x}$ films annealed at $110{ }^{\circ} \mathrm{C}$ is shown in Fig. S4 (ESI $\dagger$ ). Although obtaining less performing devices, preliminary results also pointed out the viability of using CuSCN as selective hole contact in $\mathrm{CH}_{3} \mathrm{NH}_{3} \mathrm{PbI}_{3}$ (i.e. processed by $\mathrm{PbI}_{2}$ - instead of $\mathrm{PbCl}_{2}-$ and $\mathrm{CH}_{3} \mathrm{NH}_{3}$ solution) based solar cells (Fig. S5, ESI $\dagger$ ). Therefore, the solution processed CuSCN can be suggested as a cost effective competitor to spiro-OMeTAD in perovskite solar cells. However, the reached $V_{\text {oc }}$, which is much lower (i.e. $>200 \mathrm{mV}$ below) than that for the spiro-OMeTAD-based solar cells with a similar device architecture ${ }^{28}$ appears to be the main limitation. This limitation, even higher for other inorganic hole selective contacts, ${ }^{19}$ has to be overcome in order to represent a full appealing alternative in the preparation of perovskite solar cells.

To better understand the origin of the $V_{\text {oc }}$ limitation, impedance spectroscopy (IS) analysis was performed. This technique allows decoupling processes, which take place at different characteristic times under the cell working conditions, and allows a systematic characterization focused on the device optimization..$^{28-32}$ Examples of the impedance pattern obtained for tested devices at applied voltage $V_{\text {app }}=0.35 \mathrm{~V}$ are plotted in Fig. 5a. Nyquist plots, imaginary $v s$. real part of impedance $Z^{\prime \prime}$ and $Z^{\prime}$ respectively, present two characteristic features regardless of the annealing temperatures. On one hand, the arc at high frequencies (hf), at low $Z^{\prime}$, is related to the selective contacts, with transport in the CuSCN layer ${ }^{13,33,34}$ and charge transfer at the interfaces between the selective contacts and perovskite. ${ }^{13}$ In this sense, the hf arc is also influenced by the perovskite absorbing layer. On the other hand, at low frequencies (lf) a Gerischer pattern is clearly identified. The Gerischer pattern is formed by a straight line with a $45^{\circ}$ slope followed by an arc laying below the prolongation of the straight line,$^{30}$ (Fig. 5a). The Gerischer pattern derives from the classical transmission line pattern that becomes Gerischer when the diffusion length

Table 1 Photovoltaic parameters of devices depicted in Fig. 4 and intergrated photocurrent from IPCE

\begin{tabular}{llllll}
\hline $\begin{array}{l}\text { Annealing } \\
\text { temp. }\left({ }^{\circ} \mathrm{C}\right)\end{array}$ & $\begin{array}{l}J_{\mathrm{sc}}(\mathrm{IPCE}) \\
\left(\mathrm{mA} \mathrm{cm}^{-2}\right)\end{array}$ & $\begin{array}{l}J_{\mathrm{sc}} \\
\left(\mathrm{mA} \mathrm{cm}^{-2}\right)\end{array}$ & $\begin{array}{l}V_{\mathrm{oc}} \\
(\mathrm{mV})\end{array}$ & $\begin{array}{l}\mathrm{FF} \\
(\%)\end{array}$ & $\begin{array}{l}\eta \\
(\%)\end{array}$ \\
\hline 90 & 13.04 & 12.9 & 491 & 49.0 & 3.1 \\
100 & 14.27 & 14.0 & 665 & 48.1 & 4.5 \\
110 & 18.53 & 14.4 & 727 & 61.7 & 6.4 \\
120 & 13.80 & 11.1 & 453 & 53.8 & 2.7
\end{tabular}



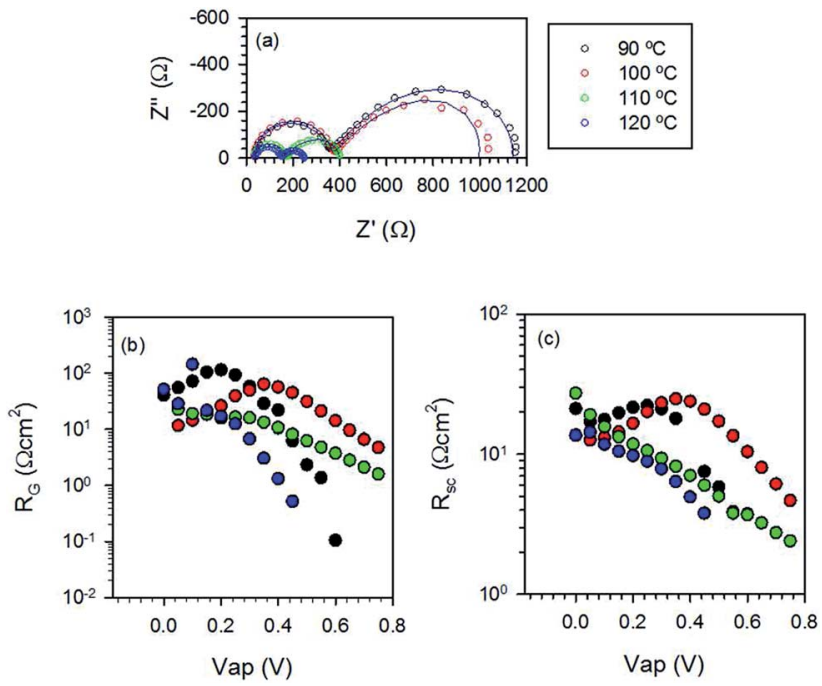

Fig. 5 (a) Nyquist plots for solar cells, annealed at different temperatures, at applied voltage $V_{\text {app }}=0.35 \mathrm{~V}$. (b) Plot of recombination resistance $\left(R_{\mathrm{G}}\right)$ vs. applied voltage and (c) plot of the resistance associated with the selective contacts $\left(R_{\mathrm{sc}}\right)$ vs. applied voltage.

is shorter than the sample thickness. ${ }^{28,30}$ This fact indicates that the cell efficiency, and especially the $V_{\text {oc }}$, is limited by the low diffusion length, shorter than the perovskite thickness.

Despite the Gerischer pattern preventing the estimation of diffusion parameters, important qualitative information about the recombination in the solar cell is contained in the Gerischer resistance, $R_{\mathrm{G}}$. Indeed, $R_{\mathrm{G}}$ is the recombination resistance, inversely proportional to the recombination rate, but it is just for the part of the sample from which charge can be collected. The obtained impedance pattern can be fitted using an $R-C$ circuit for the hf in series with a Gerischer for the lf (Fig. S6, ESI $\dagger$ ). Since a capacitor and a Gerischer are ideal elements, Constant Phase Elements (CPEs) and Gerischer plus $R-C$ were used in order to obtain a better fit, see Fig. 5a. The recombination can be qualitatively analyzed from $R_{\mathrm{G}}$, Fig. 5b. Reduction of the recombination resistance at a high potential, for cells annealed at 90 and $120^{\circ} \mathrm{C}$, indicates a recombination increase in these samples, which is in good agreement with the reduction of $V_{\mathrm{oc}}$ observed. On the other hand, Fig. 5c shows $R_{\mathrm{sc}}$, resistance associated with the selective contacts, obtained from the hf arc. This resistance is related to the charge transfer resistance between the perovskite and selective contacts ${ }^{\mathbf{1 3}}$ and transport resistance in the CuSCN layer. ${ }^{13,33,34} R_{\mathrm{sc}}$ acts as a series resistance and decreases as a function of the annealing temperature, explaining the improvement in FF as the annealing temperature increased up to $110{ }^{\circ} \mathrm{C}$. Nevertheless, additional parameters seem to contribute to the decrease of the FF in devices based on the perovskite films annealed at $120^{\circ} \mathrm{C}$. The FF drop may be mainly due to the large voids in the perovskite film (Fig. 2g) and the consequent contact between the electron and hole selective contacts. It is worth mentioning that good reproducibility of impedance results were found, by measuring several solar cells prepared under the same conditions, see Fig. S7 (ESI†).
Although less significant than $V_{\text {oc }}$ deviations, the $J_{\text {sc }}$ of the present perovskite solar cells is also lower than those reached in planar heterojunction based perovskite solar cells with spiroOMeTAD as the hole selective contact. ${ }^{25,28}$ To gain further insight into the $J_{\mathrm{sc}}$ limiting mechanism, the photoresponse spectra were measured in the $300-850 \mathrm{~nm}$ range. Fig. 6a shows the external quantum efficiency (eQE) spectra of representative solar cells based on perovskite films annealed at different temperatures. In general, an improvement in photoresponse for increasing temperatures, peaking at $110{ }^{\circ} \mathrm{C}$ annealing temperature, is noticed. Furthermore, the integrated currents (included in Table 1) are reasonably in good agreement with those obtained from the $J-V$ measurements. The largest deviation is detected for solar cells with the best performance (i.e. based on perovskite films annealed at $110^{\circ} \mathrm{C}$ ), suggesting better performance under low irradiation. In general, the eQE for wavelengths close to the perovskite absorption edge is relatively lower than that for short wavelengths. This is mainly due to the optical losses (i.e. lower absorptance for wavelengths close to the absorption edge, Fig. S9, ESI $\dagger$ ). Indeed, the relative internal quantum efficiency (riQE) i.e. eQE versus the absorptance before the $\mathrm{Au}$ contact deposition spectra show similar values for the blue and red photons, or slightly higher for the latter (Fig. 6b). It is noted that the peak centered at $\lambda \sim 780 \mathrm{~nm}$ may be overestimated because the reflections in the back contact could enhance the light harvesting in the solar cells in comparison to the glass $/ \mathrm{SnO}_{2}: \mathrm{F} / \mathrm{TiO}_{2} / \mathrm{CH}_{3} \mathrm{NH}_{3} \mathrm{PbI}_{3-x} \mathrm{Cl}_{x} / \mathrm{CuSCN}$ samples, for

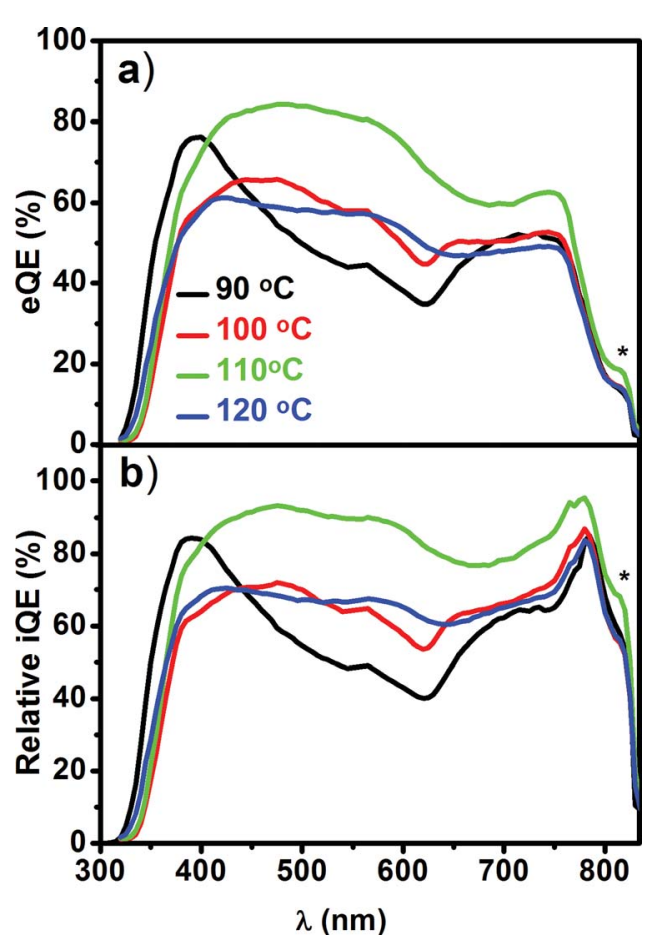

Fig. 6 (a) eQE and (b) relative $\mathrm{iQE}$ of solar cells based on different annealing temperatures of $\mathrm{CH}_{3} \mathrm{NH}_{3} \mathrm{Pbl}_{3-x} \mathrm{Cl}_{x}$ films. * The feature observed at $\sim 815 \mathrm{~nm}$ is due to an artifact in the eQE estimation (see Fig. S8, ESI $\dagger$ ). As the absorption of the glass $/ \mathrm{SnO}_{2}: \mathrm{F} / \mathrm{TiO}_{2} /$ $\mathrm{CH}_{3} \mathrm{NH}_{3} \mathrm{Pbl}_{3-x} \mathrm{Cl}_{x} / \mathrm{CuSCN}$ samples is negligible in this wavelength, the feature is stronger in the relative $\mathrm{iQE}$ value spectra. 
which we performed the optical characterization (Fig. S9†). A similar peak has been recently reported by Edri et al. for mesosuperstructured perovskite solar cells based on $\mathrm{CH}_{3} \mathrm{NH}_{3} \mathrm{PbBr}_{3}$ and $\mathrm{CH}_{3} \mathrm{NH}_{3} \mathrm{PbBr}_{3-x} \mathrm{Cl}_{x} \cdot{ }^{35} \mathrm{~A}$ valley-like shape is clearly detected in the rIQE spectra, pointing out significant losses in the collection of charges generated from green and yellow photons (i.e. especially for devices with perovskite films annealed at $\leq 100{ }^{\circ} \mathrm{C}$ ). Taking into account the variation of the penetration depth as a function of the photon wavelength, it can be assumed that blue photons are absorbed relatively close to the $\mathrm{TiO}_{2} /$ perovskite. Furthermore, the decrease of the absorptance detected for wavelengths larger than $600 \mathrm{~nm}$ (Fig. S9†) seems to suggest that the penetration depth of the red photons is comparable to the perovskite film. Therefore, the absorption of the red photons is expected to occur along all the perovskite film. In contrast, the green and yellow photons may not reach the proximities of the perovskite/CuSCN interface. Based on this assumption, a tentative model is here proposed. The photogenerated electrons from the blue photons close to the $\mathrm{TiO}_{2} /$ perovskite interface may be quickly injected into the $\mathrm{TiO}_{2}$ selective contact. The holes are then quite efficiently transported along the perovskite film until reaching the CuSCN, as the electron density is reduced (and consequently recombination probability) due to an efficient electron extraction. However, the charge collection efficiency decreases when some charge carriers are also generated in the bulk of the perovskite. Interestingly, better collection efficiency occurred when some electron-hole pairs are generated close to the perovskite/CuSCN interface. Thus, the fast hole injection to the CuSCN seems to be crucial, enhancing the collection of carriers photogenerated near to its interface, but also of those generated in the bulk of the perovskite film. Therefore, in addition to the ambipolar conduction of the perovskite film, well-balanced extraction in the selective contacts plays a vital role to reach high performance planar heterojunction perovskite solar cells. Edri et $a l^{36,37}$ reported recently a very similar charge collection profile, by using an electron beam-induced current (EBIC) technique, in planar heterojunction $\mathrm{CH}_{3} \mathrm{NH}_{3} \mathrm{PbBr}_{3-x} \mathrm{Cl}_{x}$-based solar cells. The particular two-peak EBIC profile was presented as the first direct experimental evidence of the $\mathrm{p}-\mathrm{i}-\mathrm{n}$ mode of operation for solar cells with the $\mathrm{CH}_{3} \mathrm{NH}_{3} \mathrm{PbBr}_{3-x} \mathrm{Cl}_{x}$ thickness comparable to the free charge carrier diffusion length. ${ }^{37}$ Potentially complementary insights are provided here from less specific experimental data such as the quantum efficiency spectra. Therefore, the present results and discussion may be of significant interest and utility for the perovskite solar cell community.

Particular photoluminescence measurements - by using blue excitation wavelength $(405 \mathrm{~nm})$ and different excitation configurations (i.e. illumination thorough the glass and through the CuSCN film, respectively) - were performed in order to gain further insight into the relevance of the perovskite/ CuSCN interface in the electron-hole dynamics. Fig. 7a displays the PL spectra for glass $/ \mathrm{CH}_{3} \mathrm{NH}_{3} \mathrm{PbI}_{3-x} \mathrm{Cl}_{x}$ and glass/ $\mathrm{CH}_{3} \mathrm{NH}_{3} \mathrm{PbI}_{3-x} \mathrm{Cl}_{x} / \mathrm{CuSCN}$ samples excited by the glass and CuSCN side, respectively. In general, samples with CuSCN exhibited relatively lower PL emission. However, the PL
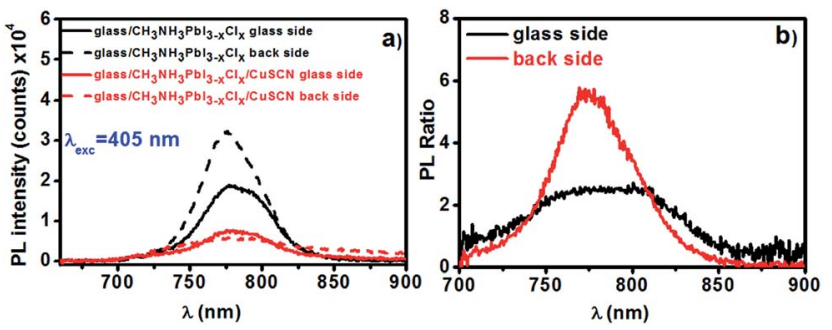

Fig. 7 (a) Photoluminescence spectra of glass $/ \mathrm{CH}_{3} \mathrm{NH}_{3} \mathrm{Pbl}_{3-x} \mathrm{Cl}_{x}$ films and glass $/ \mathrm{CH}_{3} \mathrm{NH}_{3} \mathrm{Pbl}_{3-x} \mathrm{Cl}_{x} / \mathrm{CuSCN}$ samples and (b) ratio of photoluminescence yield between glass/perovskite and glass/perovskite/ CUSCN for the different excitation configurations.

quenching (Fig. 7b) is stronger when the samples are excited through the CuSCN film. Taking into account the relative short penetration depth of the blue photons, the better hole collection when the electron-hole pair is generated close to the perovskite/CuSCN interface is confirmed. As further evidences, weak PL quenching and no significant effect of the illumination side was detected for the red excitation wavelength (i.e. $650 \mathrm{~nm}$, Fig. S10, ESI $\dagger$ ), for which electron-hole pairs are generated along the whole perovskite film irrespective of the illumination side.

All in all, improving the optoelectronic properties of the perovskite films (i.e. free charge carrier transport) and the perovskite/CuSCN interface (i.e. hole transfer) is suggested to increase the power conversion efficiency - by means of an enhancement of the free charge carrier diffusion length - of $\mathrm{TiO}_{2} / \mathrm{CH}_{3} \mathrm{NH}_{3} \mathrm{PbI}_{3-x} \mathrm{Cl}_{x} / \mathrm{CuSCN}$ solar cells. As no significant sensitivity of the solar cell performance versus the CuSCN thickness was detected (Fig. S11, ESI $\dagger$ ), the hole transport in the CuSCN film does not seem to be a major limiting factor. However, further studies are needed.

\section{Conclusions}

The viability of using solution processed CuSCN films as hole selective contacts in perovskite solar cells is demonstrated. Planar heterojunction-based glass/FTO/TiO $/ \mathrm{CH}_{3} \mathrm{NH}_{3} \mathrm{PbI}_{3-x} \mathrm{Cl}_{x} /$ CuSCN/Au solar cells with a power conversion efficiency of $6.4 \%$ have been obtained. The characterization of the devices by means of impedance spectroscopy pointed out the low diffusion length as the main origin of the modest photovoltage $(<750 \mathrm{mV})$, which is the main limiting photovoltaic parameter. However, the recombination losses are not only affected by the CuSCN, but also by the perovskite film. Furthermore, the detailed analysis of the quantum efficiency spectra suggest that the well-balanced charge carrier extraction in the selective contacts is a crucial parameter to reach high photocurrents in planar heterojunction perovskite solar cells. All in all, in addition to proposing an alternative, cost-competitive and robust hole selective contact, significant insights into the physical mechanisms involved in perovskite-based solar cells have been provided. The influence of the CuSCN layer has been emphasized, paving the way for further progress in perovskite solar cells with inorganic hole selective contacts. 


\section{Note added in proof}

During the revision of this paper, three highly relevant articles to this topic were published: S. Ito, S. Tanaka, H. Vahlman, H. Nishino, K. Manabe, P. Lund, Carbon-Double-Bond-Free Printed Solar Cells from $\mathrm{TiO}_{2} / \mathrm{CH}_{3} \mathrm{NH}_{3} \mathrm{PbI}_{3} / \mathrm{CuSCN} / \mathrm{Au}$ : Structural Control and Photoaging Effects, ChemPhysChem, 2014, 15, 1194-1200. A. S. Subbiah, A. Halder, S. Ghosh, N. Mahuli, G. Hodes, S. K. Sarkar, Inorganic Hole Conducting Layers for Perovskite based Solar Cells, J. Phys. Chem. Lett., 2014, DOI: 10.1021/jz500645n. P. Qin, S. Tanaka, S. Ito, N. Tetreault, K. Manabe, H. Nishino, M. K. Nazeeruddin, M. Gratzel, Inorganic hole conductor-based lead halide perovskite solar cells with $12.4 \%$ conversion efficiency, Nat. Commun., 2014, 5, 3834 DOI: $10.1038 /$ ncomms4834.

\section{Acknowledgements}

Financial support by the European Union (ORION CP-IP 229036-2) and Universitat Jaume I project 12I361.01/1 is gratefully acknowledged. R.T-Z. acknowledges the support of the Program "Ramon y Cajal" of the MICINN.

\section{References}

1 K. Liang, D. B. Mitzi and M. T. Prikas, Chem. Mater., 1998, 10, 403.

2 H.-S. Kim, C.-R. Lee, J.-H. Im, K.-B. Lee, T. Moehl, A. Marchioro, S.-J. Moon, R. H.- Baker, J.-H. Yum, J. E. Moser, M. Grätzel and N.-G. Park, Sci. Rep., 2012, 2, 591.

3 M. M. Lee, J. Teuscher, T. Miyasaka, T. N. Murakami and H. J. Snaith, Science, 2012, 338, 643.

4 J. Burschka, N. Pellet, S.-J. Moon, R. H. Baker, P. Gao, M. K. Nazeeruddin and M. Grätzel, Nature, 2013, 499, 316.

5 M. Liu, M. B. Johnston and H. J. Snaith, Nature, 2013, 501, 395.

6 J. T.-W. Wang, J. M. Ball, E. M. Barea, A. Abate, J. A. Alexander-Webber, J. Huang, M. Saliba, I. Mora-Sero, J. Bisquert, H. J. Snaith and R. J. Nicholas, Nano Lett., 2014, 14, 724 .

7 D. Liu and T. L. Kelly, Nat. Photonics, 2014, 8, 133.

8 http://www.nrel.gov/ncpv/images/efficiency_chart.jpg.

9 J.-H. Im, C.-R. Lee, J.-W. Lee, S.-W. Park and N.-G. Park, Nanoscale, 2011, 3, 4088.

10 A. Kojima, K. Teshima, Y. Shirai and T. Miyasaka, J. Am. Chem. Soc., 2009, 131, 6050.

11 E. Edri, S. Kirmayer, D. Cahen and G. Hodes, J. Phys. Chem. Lett., 2013, 4, 897.

12 J. H. Noh, S. H. Im, J. H. Heo, T. N. Mandal and S. I. Seok, Nano Lett., 2013, 13, 1764.

13 E. J. Juarez-Perez, M. Wußler, F. Fabregat-Santiago, K. LakusWollny, E. Mankel, T. Mayer, W. Jaegermann and I. MoraSero, J. Phys. Chem. Lett., 2014, 5, 680.

14 O. Malinkiewicz, A. Yella, Y. H. Lee, G. M. Espallargas, M. Grätzel, M. K. Nazeeruddin and H. J. Bolink, Nat. Photonics, 2014, 8, 128.
15 S. Sun, T. Salim, N. Mathew, M. Duchamp, C. Boothroyd, G. Xing, T. C. Sum and Y. M. Lam, Energy Environ. Sci., 2014, 7, 399.

16 B. Conings, L. Baeten, C. D. Dobbelaere, J. D'Haen, J. Manca and H.-G. Boyen, Adv. Mater., 2014, 26, 2041.

17 J. H. Heo, S. H. Im, J. H. Noh, T. N. Mandal, C.-S. Lim, J. A. Chang, Y. H. Lee, H.-J. Kim, A. Sarkar, M. K. Nazeeruddin, M. Grätzel and S. I. Seok, Nat. Photonics, 2013, 7, 486.

18 D. Bi, L. Yang, G. Boschloo, A. Hagfeldt and E. M. J. Johansson, J. Phys. Chem. Lett., 2013, 4, 1532.

19 J. A. Christians, R. C. M. Fung and P. V. Kamat, J. Am. Chem. Soc., 2014, 136, 758.

20 E. V. A. Premalal, N. Dematage, G. R. R. A. Kumara, R. M. G. Rajapakse, M. Shimomura, K. Murakami and A. Konn, J. Power Sources, 2012, 203, 288.

21 B. O'Regan and D. T. Schwartz, Chem. Mater., 1995, 7, 1349. 22 C. L. Clement, R. Tena-Zaera, M. A. Ryan and G. Hodes, Adv. Mater., 2005, 17, 1512.

23 Y. Itzhaik, O. Niitsoo, M. Page and G. Hodes, J. Phys. Chem. $C, 2009,113,4254$.

24 C. Chappaz-Gillot, S. Berson, R. Salazar, B. Lechene, D. Aldakov, V. Delaye, S. Guillerez and V. Ivanova, Sol. Energy Mater. Sol. Cells, 2014, 120, 163.

25 G. E. Eperon, V. M. Burlakov, P. Docampo, A. Goriely and H. J. Snaith, Adv. Funct. Mater., 2014, 24, 151.

26 J. M. Ball, M. M. Lee, A. Hey and H. J. Snaith, Energy Environ. Sci., 2013, 6, 1739.

27 A. Dualeh, N. Tetreault, T. Moehl, P. Gao, M. K. Nazeeruddin and M. Grätzel, Adv. Funct. Mater., 2014, 24, 3250.

28 V. Gonzalez-Pedro, E. J. Juarez-Perez, W.-S. Arsyad, E. M. Barea, F. Fabregat-Santiago, I. Mora-Sero and J. Bisquert, Nano Lett., 2014, 14, 888.

29 H.-S. Kim, I. Mora-Sero, V. Gonzalez-Pedro, F. FabregatSantiago, E. J. Juarez-Perez, N.-G. Park and J. Bisquert, Nat. Commun., 2013, 4, 2242.

$30 \mathrm{~J}$. Bisquert, I. Mora-Sero and F. Fabregat-Santiago, ChemElectroChem, 2014, 1, 289.

31 H.-S. Kim, J.-W. Lee, N. Yantara, P. P. Boix, S. A. Kulkarni, S. Mhaisalkar, M. Grätzel and N.-G. Park, Nano Lett., 2013, 16, 2412.

32 A. Dualeh, T. Moehl, N. Tetreault, J. Teuscher, P. Gao, M. K. Nazeeruddin and M. Grätzel, ACS Nano, 2013, 8, 362.

33 P. P. Boix, G. Larramona, A. Jacob, B. Delatouche, I. MoraSeró and J. Bisquert, J. Phys. Chem. C, 2012, 116, 1579.

34 I. Mora-Seró, S. Giménez, F. Fabregat-Santiago, E. Azaceta, R. Tena-Zaera and J. Bisquert, Phys. Chem. Chem. Phys., 2011, 13, 7162.

35 E. Edri, S. Kirmayer, M. Kulbak, G. Hodes and D. Cahen, J. Phys. Chem. Lett., 2014, 5, 429.

36 E. Edri, S. Kirmayer, A. Henning, S. Mukhopadhyay, K. Gartsman, Y. Rosenwaks, G. Hodes and D. Cahen, Nano Lett., 2014, 14, 1000.

37 E. Edri, S. Kirmayer, S. Mukhopadhyay, K. Gartsman, G. Hodes and D. Cahen, Nat. Commun., 2014, 5, 3461, DOI: 10.1038/ncomms4461. 